\title{
The Focus is the Sampling Theory in the Fields of Traditional Accounting Audit and Digital Audit: testing the Newcomb- Benford Law for the first digit of in public accounts
}

\author{
Josenildo dos Santos \\ University of São Paulo \\ Josedilton Alves Diniz \\ University of Brasília \\ Luiz J. Corrar \\ University of São Paulo
}

\begin{abstract}
The presentation and demonstration of the Newcomb-Benford Law $(1881,1938)$, as a powerful methodology in labor planning in the Audit field, were emphasized by Hill (1998), Pinkham (1961) and Raimi (1985), but its integration with tests of Hypotheses proved more effective for this purpose. For such, the purpose of this article is to present a proposal of an accounting-metric model for the fields of Financial Accounting and Digital Accounting, different from the traditional model used in Brazil. Initially, the accounting-metric, based on the relationship between the Newcomb-Benford Law and The Hypotheses tests (Z-test and Qui-square), introduced by Nigrini (2000) was evidenced. Subsequently, a practical application, using a case study for twenty municipalities of the State of Paraíba was developed to verify the effectiveness of the model presented in this work, considering a population of approximately 104 thousand pledge notes. The methodological procedure used during the development of this research was the deduction method, and, based on a practical application from the pledge notes of the municipalities of Paraíba mentioned above, abstracting the $1^{\text {st }}$ digit and applying the Newcomb-Benford law, measuring the significance level using Hypothesis Tests. It was then verified that the model adopted was capable of delineating the DNA-equivalent of the behavior of the public expenses of the municipalities being analyzed, and the accounting-metric method developed here was verified, and is effective. One thereby concluded that there is a strong sign of overinvoicing and fractioning of expenses to dodge the limit established by Federal Law No. 8666/93, which disciplines acquisitions by bid.
\end{abstract}

Key words: samply theory, audit.

Received in 17/06/2005; revised in 17/06/2005; accept in 22/06/2005. 


\section{INTRODUCTION}

he speed with which the transformations have been occurring, especially in the $\Gamma$ contemporary financial-accounting management of the entities, requires increasingly that the accounting professional seek integration of technical-scientific knowledge with other sciences. According to Horngren (1985, p. 350), "as the knowledge fields are superposed among themselves, to specify where the accounting field begins and ends always constitutes an over simplification".

It is further verified that the social, political and economic changes, the explosion of knowledge and information, the decline of State power, the globalization of domestic economies has been producing a profound impact in what one does, including in the accounting field. Hence, the need to resort to innovations in science and technology, putting them at the service of the processing of information used by the Accountant, materialized in the different statements and reports generated by accounting, in the context of management accounting.

In the context of transformations, uncertainties, crises and scandals, which the world economy has been witnessing, accounting-metric unfolds as an indispensable scientific methodology to conquer privileged space in the decision-making process by entities, as well as in seeking to identify the faithfulness of financial statements in the audit outline.

Modern management of companies and entities, nowadays, requires the use in ever more accentuated scales of the Mathematical Sciences, especially in the search for new more advanced scientific methodologies to solve emerging management problems.

Fundamentally, the accounting professional, in this mean time, he or she who dedicates him/herself to the audit sector, encounters every day situations in which, by circumstantial forces, he shall have to adopt an audit procedure to evaluate some characteristics of equity items. Depending on the number of items to be analyzed, associated to cost-benefit, the auditor will have to make use of the attributes of the sampling definition to obtain information that represent the population contemplated in this assessment, Boynton, Johnson and Kell (2004).

It should be emphasized that, to delimit a sampling, the auditor must make use of knowledge from the Mathematical Sciences (Statistics, Computing and Integrated Math), so that the control risks and the risks of breakdown tests, together with uncertainties, are technically controlled.

This article proposes the use of a methodology capable of creating a link between the mathematical models and the application of the Newcomb-Benford Law $(1881,1938)$, to test the integrity of a series of data from accounting phenomena in the fields of public accounting and Brazilian public accounting, as far as the values of the pledge notes of the municipalities of the Paraíba state are concerned, as a way to assist the public auditors to better set out the public expenses to be audited. In this work, one develops, based on the Newcomb-Benford Law (NB-Law) an Accounting Metrics model capable of determining the "DNA-equivalent" of public expenses, i.e., the way the quantitative analysis of a series of pledge notes shall behave, with view to identify the behavior on which the first digit of the pledge note shall be molded.

The development and dissemination of a methodological proposal of this nature has been little disclosed and used in the accounting audit field and in the field of accounts audit 
and public digital audit in Brazil. In fact, an anomaly of probabilities, as provided by the NBLaw, will be used as a standard-distribution of measures to detect deviation in standards (errors or fraud).

The NB-Law declares that the distribution of the frequency of digits from a random series of numbers (of a good size) behaves as a natural law. That is, the phenomenon of the frequency of digits is a natural phenomenon, i.e., any accounting phenomenon changed by man will not be in accordance with the NB-Law.

Therefore, knowing how public expenses should behave, within the NB-Law model, the uncertainties inherent to audits should be considerably reduced, since by knowing the group of expenses which do not conform to the model proposed here, the definition of sampling will have a clearer direction and may be united to traditional sampling techniques in auditing.

\section{JUSTIFICATION OF THE RESEARCH}

The relevance of this research meets the systemizing of the instructors of Audit works, when the application of the Newcomb-Benford Law is present and when one of the objectives- of the Audit - is to detect tax evasion (signs of fraud), using Accounting Metrics as a tool. It should not be forgotten that the performance of an Audit does not relate only to the detection of accounting frauds or manipulation of accounts. It also works as a control mechanism of the company's internal and external processes, serving as an instrument for diagnosis and correction.

With the enhanced efficiency of the Newcomb-Benford Law, in its application in Audits, by using Hypothesis Tests, there are several advantages which the Auditor can enjoy, among which one may cite the following:

- remove partiality from conclusions about the verisimilitude of accounts audited;

- time optimization, since a discrepancy detected by the comparison of the distributions observed $\left(\mathrm{p}_{\mathrm{o}}\right)$ and expected $\left(\mathrm{p}_{\mathrm{e}}\right)$, according to the Newcomb-Benford Law does not firmly suggest the existence of tax evasion and accounting fraud. The error may be random or result from the type of sampling used;

- the Auditor succeeds in imprinting greater scientificity in his works, thus issuing his opinion with greater consistency.

\section{METHODOLOGICAL PROCEDURES}

In this investigation, one developed a different proposal from that used traditionally in Brazilian accounting. For such, this work presents and demonstrates the Newcomb-Benford Law as a powerful method to help the accountant and the auditor plan his works. Moreover, it will be used as the cornerstone for an Accounting Metrics model, introduced by Nigrini (2000), which is based on the relationship between the Newcomb-Benford Law and Hypothesis Tests (Z-test and Qui-square test) in the context of analyzing data, thus offering consistency in the acceptance of an Accounting Metrics model constructed herein - simplified and adapted to Brazilian public accounting conditions.

An application of a practical nature, in the context of positive accounting, was performed so as to evidence the premises that the behavior of these public expenses follows the conceptual structure presented by the NB-Law. 
This article has basic axes:

a) the study of the Newcomb-Benford Law $(1881,1938)$;

b) the development of an Accounting Metrics model similar to that created by Nigrini (2000), which is based on the relationship between the Newcomb-Benford Law and Hypothesis Tests (Z-Test and $\chi^{2}$-Test) in the context of Accounting Audits;

c) the application of the Accounting Metrics model to 20 municipalities distributed in the Coastal regions and regions of the interior of the Paraíba State, as far as the analysis of the value of pledge notes is concerned.

Analysis of the differences between the distributions of probabilities observed (po) and expected (pe), according to the Newcomb-Benford Law, studied from Hypothesis Tests. More precisely, the Z-Test is used to measure the degree of significance among differences $p_{o}-p_{e}$, so as to define the following hypotheses:

$\mathrm{H}_{\mathrm{o}} \rightarrow$ Statistically, there is no significant difference between the po-pe differences in the distribution of probabilities observed (po) and expected (pe);

$\mathrm{H}_{1} \rightarrow$ There is a statistically significant difference between the po-pe differences in the probability distributions observed (po) and expected (pe);

By denoting the hypothesis system from the usual semiology, one has

$$
\begin{aligned}
& \mathrm{H}_{0}: \mathrm{p}_{\mathrm{o}}=\mathrm{p}_{\mathrm{e}} \\
& \mathrm{H}_{1}: \mathrm{p}_{\mathrm{o}} \# \mathrm{p}_{\mathrm{e}}
\end{aligned}
$$

To study the level of significance among the $\mathrm{p}_{\mathrm{o}}-\mathrm{p}_{\mathrm{e}}$ differences, one uses the $\mathrm{Z}-$ Test.

Provided that,

$$
Z=\frac{\left|p_{o}-p_{e}\right|-\frac{1}{2 n}}{\sqrt{\frac{p_{e}\left(1-p_{e}\right)}{n}}}
$$

$\mathrm{n}$ is the number of observations;

$\frac{1}{2 \mathrm{n}}$ is the continuity correction term and is only used when it is lower than $\mid$ po - pe $\mid$.

The level of significance is $\alpha=0.05$ and critical $\mathrm{Z}_{\mathrm{c}}$ is equal to 1.96 .

To find out if the two probability distributions in their totality are in accordance with the other, or if the probability distribution observed $\left(\mathrm{p}_{\mathrm{o}}\right)$ is "equal" to the expected distribution $\left(\mathrm{p}_{\mathrm{e}}\right)$, according to the Newcomb-Benford Law, one uses the $\chi^{2}-$ Test as follows:

$$
\begin{aligned}
& 9 \\
& \chi^{2}=\sum(\mathrm{PO}-\mathrm{PE})^{2}, \\
& \mathrm{~d}=1 \quad \mathrm{PE}
\end{aligned}
$$

Where PO and PE are the proportions observed and expected defined by: 
$\mathrm{PO}=\left(\mathrm{p}_{\mathrm{o}}\right) \times($ population number $)$

$\mathrm{PE}=\left(\mathrm{p}_{\mathrm{e}}\right) \mathrm{x}($ population number $)$

The level of significance is $\alpha=0.05$, the degree of liberty is 8 and the critical values of the $\chi^{2}$ is 15.507 .

Finally, in the practice of Accounting Audit, the Accounting Metrics model developed here was used in a population consisting of 20 (twenty) municipalities of the State of Paraíba, located in the coastal and interior regions, totaling 104,104 observations (values of the pledge notes). This stage of the practical nature was performed to evidence the premises established during the development of this work. The deductive reasoning was the guiding line which governed the entire development of this research, based on the knowledge of the Mathematical Sciences, which evidenced the truthfulness of the results obtained.

\section{REVISION OF THE LITERATURE}

\subsection{Quantitative Methods Applied to Accounting}

One knows that the public expense values, materialized in the pledge notes, can be easily manipulated by public managers, using artifices that are not always ethical or legal for compliance with certain legal determinations, according to their interests. For example, one wishes that a certain expense, subject to bidding, be fractioned to avoid the legal procedure instituted by bidding law.

There will always be accountants and public agents who will use these procedures. However, we cannot fail to ignore, at this time, that one is always seeking to implement scientific methodologies or effective tools in determining signs of accounting manipulation and consequently repression of fraudulent conduct.

There has been much discussion, nowadays, about the use of Quantitative Methods to assist the so-called Social Sciences, and there are criticisms and rejections of the use of such procedures, very often deeply rooted in ignorance with respect to their effectiveness, or simply due to resistance to change in the how to do or in the learning of knowledge, which formally belong to an other area of human knowledge (in the Natural Sciences, this last factor is also known as Inertia). Matz, Curry and Frank affirm that:

Company directors are beginning to use the mathematical models as an instrument to describe and assist in control transactions. For example, the models or simulations make it possible to test several inventory control policies and to estimate techniques in past experience as well as to select the method that best meets the administration's objectives.

In this line, Ackoff and Sasieni (1996) introduce the importance of quantitative models to abstract a result from the analysis of data; otherwise let us see:

\footnotetext{
Models are representations of reality. If they were so complex and difficult to control as reality, there would be no advantage in using them. Fortunately, generally speaking, we can build models that are much simpler than reality and thus we succeed in using them to predict and explain phenomena with a high degree of precision. The reason for this is that, although a large number of variables is necessary to predict a phenomenon with perfect precision, a small number of variables explains the greatest part of them. Evidently, the trick is to find certain variables and the relationship between them.
} 
One can then infer that a guiding characteristic of scientific investigation of prediction, in other words, the definition of models to adopt, presents a cyclical and interactive character, as noted below in the following diagrams:

\section{DIAGRAM 1}

\section{Relationship between the physical and scientific worlds.}

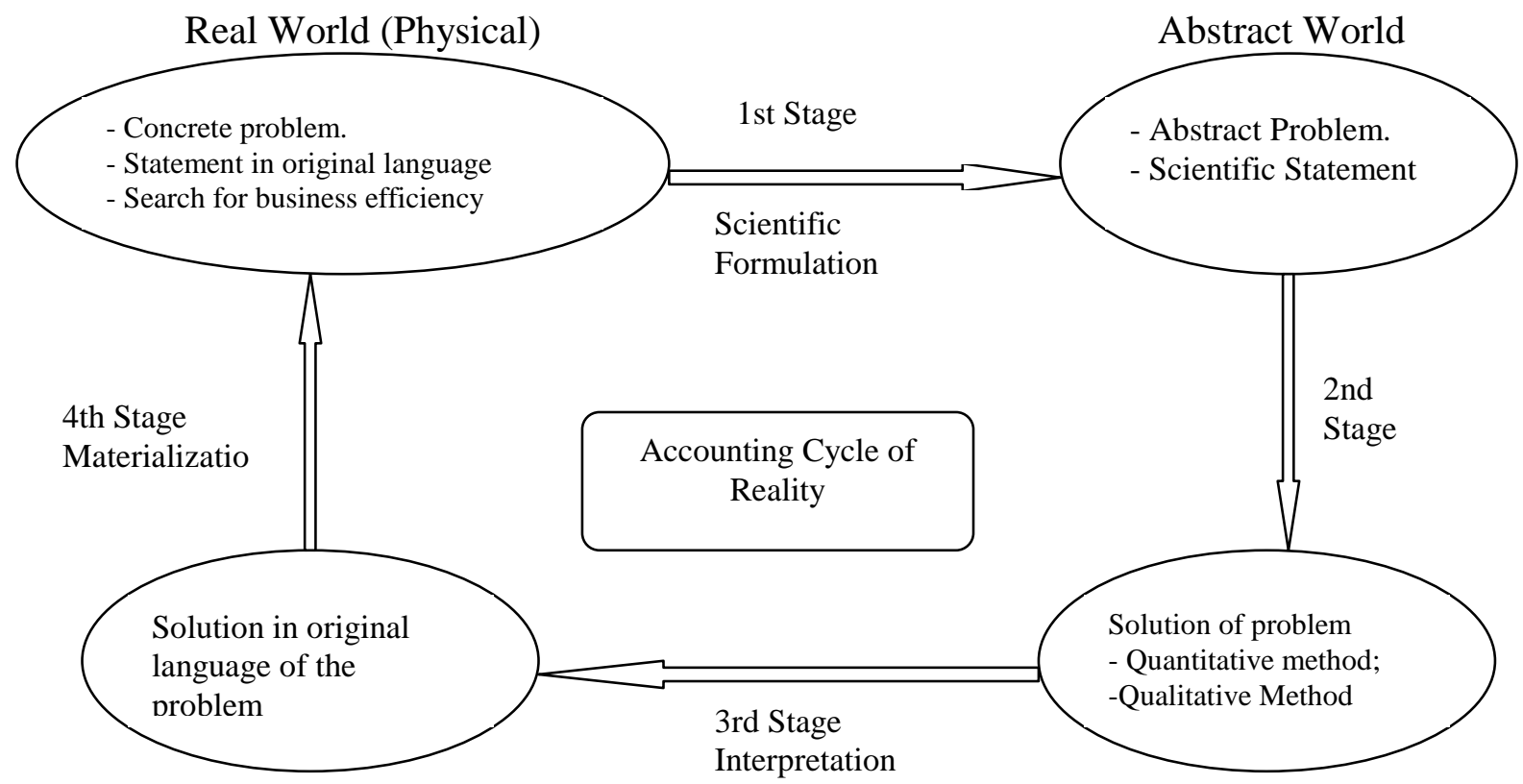

Source: Santos, Diniz and Ribeiro Filho (2003)

Thus, the qualitative methods apply to the prediction models specially important when the historical data are not available. In fact, these methods are seen as highly subjective and subject to evaluation. On the other hand, the quantitative prediction methods make use of historic data, so that one minimizes the subjectivity of the model significantly.

\subsection{Audit Sampling}

The audit sampling, as defined by AICPA SAS (AU 350), Audit Sampling, consists in a procedure applied to less than $100 \%$ of the items that compose a balance of an account or class of transactions, to assess some of the balance or class characteristics. In fact, most of the time, it is not necessary to analyze the entire population; all that is necessary is to analyze part of it to convince the auditor.

Thus, the sampling is applied both to control and substantive tests. However, the sampling is equally applied to all audit procedures, which may be used in performing these tests, Boynton, Johnson and Kell (2004).

In Brazilian public auditing, sampling is widely used for confirmation and tracking, but when one uses the skill of questioning, observation tests and analytical revision procedures are used much less. 
In the audit process, one can use sampling to obtain information about many different characteristics of the population. However, most of the samples lead to the estimate of a deviation rate in a population or monetary value of a population (monetary value of errors in a population). However, the NB-Law, across its conceptual extension, has a mechanism capable of attenuating such deviations, given that it delineates the monetary behavior of the population and samples.

Therefore, the use of samples is still the most logical path: when one wants to evidence the physical existence of data and their appreciation in a reasonable period of time. However, with the use of samples (even if these are significant) in the audit works, one cannot discard the possibility of the occurrence of errors, which may lead the Auditor to conclusions that do not represent reality. This is because population items vary.

Thus, in estimating the probability of the occurrence of a certain event corresponding to a certain item of the population being tested (departing from the sample), one must these variations into consideration and it is necessary that the possible error committed be estimated.

These errors may occur or be considered as a function of the type of sample chosen by the Auditor (which may result from a particular probability, or not) or may be related to both randomness and non-representativeness of its size, i.e., the sample size may not be sufficient to guarantee trustworthy conclusions about the population (which is the whole about what one intends to infer), to which, once again, one must draw the Auditor's attention.

From this viewpoint, Santos, Diniz and Ribeiro Filho (2003) have stated that a reasonable way for the Auditor to orient himself is to use Accounting Metrics as a scientific methodology to minimize errors. To defeat such deviations, one used in this research Hypothesis Tests, which permitted to analyze the degree of significance of the differences that may occur between the expected probability distributions (pe), based on the NewcombBenford Law, and the observed ones $\left(\mathrm{p}_{\mathrm{o}}\right)$ of the accounting phenomenon being audited, in order to verify standard deviations in the pledge notes of the entire population, corresponding to the entities mentioned above. This is one of the great advantages of this model, instituting an innovation in audit techniques.

In other words, the analysis conducted by the entities is based on the following pillars: comparison of observed and expected distributions, according to the Newcomb-Benford Law; and evaluation of the significance of the differences between the observed (real) probabilities, $\mathrm{p}_{\mathrm{o}}$, and expected probabilities, $\mathrm{p}_{\mathrm{e}}$, according to the Newcomb-Benford Law.

\subsection{Intuitive Interpretation of the Newcomb-Benford Law}

The Newcomb-Benford Law is an anomaly of probabilities, resulting in that the digits 1,2 and 3 are more common than the digits 4, 5, $6 \ldots 9$ as first digit of a distribution of numbers of a good size. That is, the chance of a number having been taken randomly and the first significant digit being 1,2 and 3 is of approximately $60.2 \%$. This phenomenon was discovered empirically by the astronomer and mathematician Simon Newcomb (1881), when he randomly observed that the first pages of the logarithmic tables, in the libraries, were more used, because they handled more, (dirtier than the others). People sought much more the logarithms that start with 1 than those that start with the digit 9. This was also verified by the physicist Frank Benford (1938), after he was 57 years old, independently of Newcomb, but 
Benford's work was a deeper one, since he had studied a set of 20,229 observations from different source: river areas, house numbers of a street, numbers of article in a magazine and others. Unlike Newcomb's, his work was widely published and applied by other researchers. In short, this article not only presents the Newcomb-Benford Law, it also describes its application in the context of Accounting Audit, Newcomb (1881), Benford (1938), Hill (1998), Nigrini (2000), Pinkham (1961) and Raimi (1985).

\subsection{Analyzing the First Digit Phenomenon Deductively}

The purpose of this work makes it imperative for one to clarify certain questions, for example: Is it not so that any of the nine digits, $1,2,3, \ldots, 9$, have the same probability of occurrence as the first significant digit of a number? Common sense says yes, but real phenomena show that this is not so. Therefore, why should a number chosen randomly have a greater probability to start with the first digits: 1, 2 and 3? In this context, only the Mathematical Sciences can really settle these doubts once and for all. For such, a mathematical justification will be given for the Newcomb-Benford Law, without the rigors of Probability Theory, since this does not fit into the context of Accounting Metrics.

Research in the field of Probability Theory Hill $(1992,1998)$, Pinkham (1961) and Raimi $(1969,1985)$ show that the Newcomb-Benford law applies to the set of data with the following properties: (a) invariable scalar potential; (b) comes from a choice from a variety of choices. This result is achieved from a stricter analysis of the Central Limit Theory, in the form of theorems for the mantissa of random variables on the multiplication effect. In this sense, when the number of variables grows, the density function tends to logarithmic distribution. Hill (1996) demonstrated rigorously that the "distribution of distribution" obtained from random samples from a variety of different distributions is the NewcombBenford distribution.

\subsection{Demonstration of the Newcomb-Benford Law}

Suppose that there is a universal probability distribution $\mathrm{p}(\mathrm{x})$ in the set of numbers characterized above. Then, $\mathrm{p}$ is an invariable scalar potential (Pinkham, 1961), that is:

(1) $\mathrm{p}(\mathrm{kx})=\lambda(\mathrm{k}) \mathrm{p}(\mathrm{x})$, for a real function of the real variable $\lambda$.

As one can suppose that :

(normalization hypothesis)

$$
\begin{aligned}
& \int p(x) d x=1 \\
& \text { whence, } \frac{1}{k} \int p(u) d u=\lambda(k) \int p(x) d x
\end{aligned}
$$

One goes on to change the variable $\mathrm{u}=\mathrm{kx}$ in the first integral, which:

$$
\int p(k x) d x=\int \lambda(k) p(x) d x
$$

This results in: $\quad(k)=\frac{1}{k}$ 
Deriving equation (1) in the variable k, one obtains:

$$
p^{\prime}(k x) \cdot x=\lambda^{\prime}(k) \cdot p(x)
$$

and for $\mathrm{k}=1$, the differential equation results:

$$
x p^{\prime}(x)=-p(x)
$$

Resolving (2), comes:

$$
\begin{aligned}
& \int_{1}^{x} \frac{p^{\prime}(t) d t}{p(t)}=\int_{1}^{x} \frac{1}{t} d t \\
& \operatorname{Ln} \mathrm{p}(\mathrm{x})=-\operatorname{Ln} \mathrm{x}
\end{aligned}
$$

Therefore, $\mathrm{p}(\mathrm{x})=\frac{1}{x} \quad$ is the solution of $(2)$.

Note that the distribution $\mathrm{p}(\mathrm{x})=1 / \mathrm{x}$ does not represent a distribution of proper probability, but with the real phenomena imposes a cut point in the distribution. One can thus consider this distribution for purposes of calculating the probabilities for the occurrence of the first digit. Then:

$$
\begin{aligned}
\text { P (first significant digit }=\mathrm{d})= & \frac{\int_{d}^{d+1} p(x) d x}{\int_{1}^{10} p(x) d x}=\frac{\ln (d+1)-\ln (d)}{\ln (10)-\ln (1)} \\
= & \frac{\ln \left(\frac{d+1}{d}\right)}{\ln (10)}=\log 10\left(1+\frac{1}{d}\right)
\end{aligned}
$$

Therefore, in particular, it is demonstrated that the probabilities of 1, 2 and 3 being the first digits of a number are: $\log _{10} 2=0.30103, \log _{10} 1.5=0.176091$ e $\log _{10} 4 / 3=0.124939$, respectively. This answers the questions above. Moreover, the Newcomb-Benford Law is deduced in a simplified manner. 


\subsection{A Geometrical Scheme for the Newcomb-Benford Law}

Although there are many "long and erudite explanations" of the Newcomb-Benford Law in the literature, especially in the USA, it can be explained simply by the following geometrical scheme:

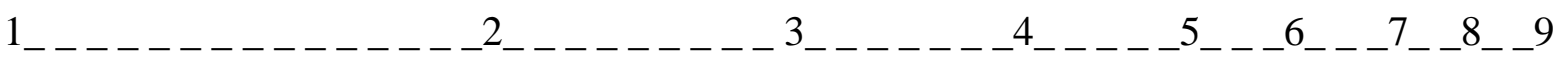

In fact, a subjacent premise of the distribution of occurrences in accordance with the Newcomb-Benford law is that the population will be distributed with reasonable uniformity in a logarithmic scale. Consequently,

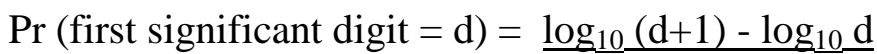

$$
\begin{aligned}
& \log _{10} 10-\log _{10} 1 \\
& =\log _{10}(1+1 / d)
\end{aligned}
$$

Thus:

$$
\begin{aligned}
& \operatorname{Pr}(\text { first significant digit }=1)=\log _{10}(1+1)=\log _{10} 2 \\
& \operatorname{Pr}(\text { first significant digit }=2)=\log _{10}(1+1 / 2)=\log _{10} 3 / 2=\log _{10} 1.5
\end{aligned}
$$

Then, this proves the work of Newcomb, in 1881, when the logarithmic values, beginning with the digits from 1 to 9 , are plotted in a logarithmic scale as follows:

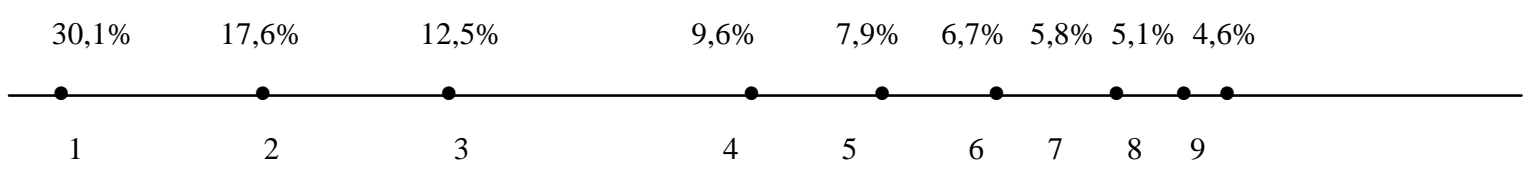

This means, for example, that all the numbers beginning by the digit 1 occupy $30.1 \%$ of the total size of this scale. In particular, numbers such as $1.8005,1.534$ and 1.21 are in this region.

\section{V . ANALYSIS OF THE DATA FROM THE RESEARCH:}

In this work, one took a population composed by 20 (twenty) municipalities of the State of Paraíba, who are located in the Coastal and interior regions, totaling 104.104 observations (values of the pledge notes).

From the choice of these cities, one considered the pledge note values, abstracting the first digit ${ }^{1}$ from the value of the expense corresponding to that pledge, grouping them to a same level of digits. This procedure was performed to treat the data in accordance with the application of the Accounting Metrics model, built here based on the Newcomb-Benford Law.

${ }^{1}$ For example: from the value $\mathrm{R} \$ 563,26$ the digit "5" was detached, and so forth. 
The results obtained from the application of the Accounting Metrics' model proposed herein in the municipalities of the State of Paraíba follow. They were the object of this research on the possibility of overinvoicing in these pledge notes.

Case 1: Analyzing the pledge notes of the Coastal Region - Year- 2002.

\section{TABLE 1}

Application of the Newcomb-Benford Law in the municipalities of the Coastal Region $\mathrm{Z}$-TEST, critical $\mathrm{Z}$ equals 1.96

\begin{tabular}{|c|c|c|c|c|c|c|c|c|c|c|}
\hline $\begin{array}{c}\text { Municipality } \\
\text { Digits }\end{array}$ & L1 & L2 & L3 & L4 & L5 & L6 & L7 & L8 & L9 & L10 \\
\hline 1 & 0,015 & 1,123 & 2,275 & 3,357 & 3,514 & 0,127 & 1,699 & 4,012 & 1,943 & 2,525 \\
\hline 2 & 3,214 & 2,868 & 3,507 & 2,479 & 0,15 & 2,232 & 0,357 & 0,589 & 2,864 & 3,874 \\
\hline 3 & 5,453 & 3,194 & 2,271 & 0,875 & 5,069 & 0,775 & 5,814 & 3,005 & 3,289 & 3,821 \\
\hline 4 & 3,402 & 1,563 & 3,525 & 3,794 & 1,068 & 0,197 & 4,082 & 1,018 & 3,384 & 0,391 \\
\hline 5 & 6,149 & 4,243 & 1,052 & 5,487 & 0,212 & 1,928 & 1,034 & 0,261 & 5,151 & 9,78 \\
\hline 6 & 1,131 & 3,109 & 0,034 & 4,491 & 1,265 & 0,03 & 2,259 & 1,205 & 2,768 & 5,9 \\
\hline 7 & 3,998 & 3,999 & 2,713 & 2,511 & 1,63 & 1,096 & 2,11 & 0,301 & 2,535 & 9,025 \\
\hline 8 & 2,931 & 1,387 & 1,555 & 1,856 & 0,035 & 0,263 & 0,293 & 0,67 & 1,335 & 2,381 \\
\hline 9 & 13,447 & 1,707 & 0,041 & 1,949 & 1,509 & 1,853 & 0,99 & 0,336 & 18,043 & 9,061 \\
\hline
\end{tabular}

TABLE 2

Application of the Newcomb-Benford Law in the pledge note amounts of the Costal Region municipalities - Year 2002 $\chi^{2}$ - TEST, critical $\chi^{2}$ equals 15.507.

\begin{tabular}{|c|c|c|c|c|c|c|c|c|c|c|}
\hline $\begin{array}{c}\text { Municipality } \\
\text { Digits }\end{array}$ & L1 & L2 & L3 & L4 & L5 & L6 & L7 & L8 & L9 & L10 \\
\hline 1 & 0,00 & 0,97 & 3,851 & 7,924 & 8,897 & 0,00 & 2,003 & 11,395 & 2,648 & 4,258 \\
\hline 2 & 8,35 & 7,03 & 10,112 & 5,041 & 0,017 & 4,3 & 0,071 & 0,268 & 6,671 & 12,027 \\
\hline 3 & 26,74 & 8,477 & 4,77 & 0,587 & 23,28 & 0,46 & 30,478 & 8,378 & 9,936 & 13,609 \\
\hline 4 & 10,07 & 2,148 & 10,96 & 13,791 & 0,886 & 0,04 & 14,746 & 0,81 & 9,427 & 0,112 \\
\hline 5 & 35,82 & 16,334 & 0,975 & 28,888 & 0,019 & 3,1 & 1,258 & 0,167 & 23,838 & 90,831 \\
\hline 6 & 1,06 & 9,85 & 0,003 & 19,192 & 1,701 & 0,01 & 4,498 & 1,604 & 6,827 & 31,378 \\
\hline 7 & 14,37 & 16,051 & 6,569 & 5,826 & 2,44 & 1,11 & 4,439 & 0,058 & 5,977 & 75,935 \\
\hline 8 & 8,12 & 1,679 & 2,259 & 3,4 & 0,019 & 0,11 & 0,047 & 0,33 & 2,163 & 6,301 \\
\hline 9 & 177,36 & 3,29 & 0,005 & 4,168 & 2,076 & 2,9 & 1,085 & 0,047 & 317,578 & 76,303 \\
\hline Total $\chi^{2}$ & 281,89 & 65,829 & 39,504 & 88,817 & 39,335 & $12,03 *$ & 58,625 & 23,057 & 385,065 & 310,754 \\
\hline
\end{tabular}

Analyzing the data from Table - 1 and 2, one finds that the Z-TEST shows the differences for each statement of pledged expenses, defined from the first digit abstracted for the study. Thus, it is possible to identify the municipalities, which, in their set of expenses, present significant differences, defined pursuant to the NB Law and to the Accounting Metrics model defined in Santos et all(2003). 
Table 3

\begin{tabular}{|c|l|}
\hline Digit & Municipalities \\
\hline 1 & L3, L4, L5, L8 and L10 \\
\hline 2 & L1, L2, L3, L4, L6, L9 and L10 \\
\hline 3 & L1, L2, L3, L5, L7, L8, L9 and L10 \\
\hline 4 & L1, L3, L4, L7 and L9 \\
\hline 5 & L1, L2, L4, L9 and L10 \\
\hline 6 & L2, L4, L7, L9 and L10 \\
\hline 7 & L1, L2, L3, L4, L7, L9 and L10 \\
\hline 8 & L1 and L10 \\
\hline 9 & L1, L9 and L10 \\
\hline
\end{tabular}

Generally, in these cases, there is sufficient evidence to reject the null hypothesis. Moreover, it is verified that the digits which the majority of municipalities has problems with are 2, 3 and 7. However, for digit 9, municipalities L1 and L9, the statistical measure of the significance level Z-TEST assumes exaggerated values, confirming a strong tendency of overinvoicing in the pledge notes of these municipalities.

On the other hand, the $\chi^{2}$ - TEST shows that there is sufficient evidence to reject the hypothesis that the distribution of the values of the pledge notes is not compatible with the distribution, according to the Newcomb-Benford Law, for the municipalities in question, except for municipality L6, whose $\chi^{2}=12.03$. This exception was due to a serious intervention by the Court of Audit of the State of Paraíba in the accounts of municipality L6.

With the analysis described above, it is possible to plan inserting a technique with scientific validation. However, if an auditor had to define a sample, for example in municipality L7, according to the model proposed herein, he would have grounds to increase the sample size for the pledges beginning with digits " 3 ", " 4 ", " 6 " and "7". If, from a different viewpoint, the auditor understands that it is possible to work with a significance level $\alpha=0.01$ and critical $\mathrm{Z}_{\mathrm{c}}$ equals 2.58 , only digits " 3 " and " 4 " would deserve special attention, developing thus, a greater concentration of audit tests for these expense statements. 
Case 2: Analyzing the pledge notes of the Interior Region of the State of Paraíba-Year -2002.

\section{TABLE 4}

Application of the Newcomb-Benford Law in the Interior Region municipalities. ZTEST, critical $Z$ equals 1.96.

\begin{tabular}{|c|l|l|l|l|l|l|l|l|l|l|}
\hline $\begin{array}{l}\text { Municipality } \\
\text { Digits }\end{array}$ & S1 & S2 & S3 & S4 & S5 & S6 & S7 & S8 & S9 & S10 \\
\hline 1 & 3,131 & 3,098 & 2,268 & 4,223 & 5,88 & 0,5 & 0,947 & 2,364 & 1,54 & 0,178 \\
\hline 2 & 5,037 & 3,213 & 2,246 & 1,627 & 1,615 & 4,591 & 5,071 & 3,016 & 2,707 & 3,433 \\
\hline 3 & 2,886 & 1,76 & 2,213 & 0,355 & 5,794 & 2,46 & 2,822 & 3,278 & 5,67 & 1,042 \\
\hline 4 & 1,959 & 3,634 & 1,64 & 4,001 & 0,847 & 2,749 & 8,96 & 2,578 & 1,948 & 5,305 \\
\hline 5 & 1,752 & 0,511 & 0,884 & $4,855^{*}$ & 1,894 & 1,717 & 0,583 & $7,115^{*}$ & 1,416 & 1,926 \\
\hline 6 & 1,248 & 1,736 & 0,708 & 1,223 & 0,378 & 0,917 & $3,733^{*}$ & 0,74 & 1,787 & 1,728 \\
\hline 7 & 2,251 & 0,801 & 1,548 & 3,187 & 5,303 & 2,981 & 1,147 & 0,516 & 4,133 & 5,968 \\
\hline 8 & 0,931 & 0,403 & 1,645 & 1,675 & 0,044 & 7,947 & 1,723 & 0,257 & 4,392 & 0,372 \\
\hline 9 & 2,767 & 2,072 & 1,139 & 4,754 & 1,196 & 15,596 & 3,132 & 1,496 & 3,992 & 2,062 \\
\hline
\end{tabular}

\section{TABLE 5}

Application of the Newcomb-Benford Law in the values of the pledge notes of the Interior Region municipalities Year 2002 $-\chi^{2}$ TEST. Critical $\chi^{2}$ equals 15.507.

\begin{tabular}{|c|c|c|c|c|c|c|c|c|c|c|}
\hline $\begin{array}{c}\text { Municipalities } \\
\text { Digits }\end{array}$ & $\mathbf{S}_{\mathbf{1}}$ & $\mathbf{S}_{\mathbf{2}}$ & $\mathbf{S}_{\mathbf{3}}$ & $\mathbf{S}_{\mathbf{4}}$ & $\mathbf{S}_{\mathbf{5}}$ & $\mathbf{S}_{\mathbf{6}}$ & $\mathbf{S}_{\mathbf{7}}$ & $\mathbf{S}_{\mathbf{8}}$ & $\mathbf{S}_{\mathbf{9}}$ & $\mathbf{S}_{\mathbf{1 0}}$ \\
\hline 1 & 6,87 & 6,89 & 3,657 & 12,412 & $24,178^{*}$ & 0,19 & 0,621 & 4,166 & 1,689 & 0,027 \\
\hline 2 & 20,78 & 8,843 & 3,989 & 2,114 & 2,044 & 16,39 & 21,109 & 7,71 & 6,388 & 10,347 \\
\hline 3 & 7,37 & 2,883 & 4,189 & 0,165 & 30,349 & 5,77 & 6,804 & 9,705 & 27,846 & 1,207 \\
\hline 4 & 3,71 & 11,98 & 2,422 & 14,652 & 0,722 & 7,87 & 74,399 & 6,556 & 3,505 & 24,664 \\
\hline 5 & 2,87 & 0,229 & 0,612 & 21,129 & 3,409 & 3,05 & 0,351 & 46,449 & 1,732 & 3,878 \\
\hline 6 & 1,52 & 3,202 & 0,684 & 1,473 & 0,112 & 1,16 & 13,699 & 0,483 & 3,274 & 2,885 \\
\hline 7 & 5,31 & 0,821 & 2,31 & 10,214 & 27,621 & 7,24 & 1,302 & 0,316 & 16,478 & 34,306 \\
\hline 8 & 0,71 & 0,141 & 2,485 & 3,048 & 0,00 & 62,66 & 3,167 & 0,056 & 17,902 & 0,088 \\
\hline 9 & 6,88 & 4,325 & 1,475 & 22,662 & 1,277 & 239,96 & 9,351 & 2,279 & 14,428 & 4,436 \\
\hline Total $\chi^{2}$ & 56,01 & 39,314 & 21,823 & 87,869 & 89,712 & 339,27 & 130,80 & 77,72 & 93,242 & 81,838 \\
& & & $*$ & & & $*$ & 3 & & 1 & \\
\hline
\end{tabular}

Conducting the same analysis already conducted in the previous tables, it is possible to identify the statistical measure of the Z-TEST, showing the $\mathrm{P}_{\mathrm{o}}-\mathrm{P}_{\mathrm{e}}$ differences, corresponding to the $1^{\text {st }}$ digit of the public expenses made in the fiscal year 2002 and which, from the viewpoint of Accounting Metrics, present significant differences, namely: 
Table 6

\begin{tabular}{|r|l|}
\hline Digit & Municipalities \\
\hline 1 & S1, S2, S3, S4, S5, S7 and S8 \\
\hline 2 & S1, S2, S3, S6, S7, S8, S9 and S10 \\
\hline 3 & S1, S3, S5, S6 S7, S8 and S9 \\
\hline 4 & $\mathrm{~S}_{2}, \mathrm{~S}_{4}, \mathrm{~S}_{6}, \mathrm{~S}_{7}, \mathrm{~S}_{8}$ and $\mathrm{S}_{10}$ \\
\hline 5 & $\mathrm{~S}_{4}$ and $\mathrm{S}_{8}$ \\
\hline 6 & $\mathrm{~S}_{7}$ \\
\hline 7 & $\mathrm{~S}_{1} \mathrm{~S}_{4}, \mathrm{~S}_{5}, \mathrm{~S}_{6}, \mathrm{~S}_{9}$ and $\mathrm{S}_{10}$ \\
\hline 8 & $\mathrm{~S}_{6}$ and $\mathrm{S}_{9}$ \\
\hline 9 & $\mathrm{~S}_{1}, \mathrm{~S} 2, \mathrm{~S} 4, \mathrm{~S} 6, \mathrm{~S} 7, \mathrm{~S} 9, \mathrm{~S} 10$ \\
\hline
\end{tabular}

Generally, the Z-TEST shows that there is sufficient evidence to reject the null hypothesis: $\mathrm{P}_{\mathrm{o}}$ $-\mathrm{P}_{\mathrm{e}}$.

The statistical measure $\chi^{2}$ - Test shows that there is sufficient evidence the hypothesis that the distribution of the pledge note values observed is not compatible with the distribution, according to the lei de Newcomb-Benford Law, for all the interior region municipalities of the state of Paraíba, studies in this work.

It should be emphasized that the municipality with the lowest value in the $\chi^{2}$ - Test is $S_{3}$ with $\chi^{2}$ $=21.823$, and the municipality with the highest value of the $\chi^{2}$ - Test is $S_{6}$ with $\chi^{2}=339.27$. A deeper analysis of the $\mathrm{Z}$ and $\chi^{2}$ values leads one to suspect that there is strong evidence that municipality S6 has overinvoiced its pledged notes, while municipality S3 has fragmented its pledge notes not to reach the bidding limit required by law, which is a fact that the auditor must implement a bigger number of tests to evidence the "breach" of natural law and of the Newcomb-Benford law.

Case 3: Analyzing the pledge notes of the 20 municipalities of the state of Paraíba by Region and as a whole:

TABLE 7

Coastal Region

\begin{tabular}{|c|c|c|c|c|c|c|c|}
\hline Digit & $\begin{array}{c}\text { Quantity } \\
\text { Observed }\end{array}$ & $\begin{array}{c}\text { Newcomb- } \\
\text { Benford } \\
\text { Law }\end{array}$ & $\begin{array}{c}\text { Proportion } \\
\text { Observed }\end{array}$ & Deviation & $\begin{array}{c}\mathbf{Z} \\
\text { Value }\end{array}$ & $\begin{array}{c}\text { Expected } \\
\text { Count }\end{array}$ & $\chi^{2}$ \\
\hline 1 & 16.554 & 0,301 & 0,298 & $-0,003$ & 1,538 & 16.743 & 2,143 \\
\hline 2 & 9.602 & 0,176 & 0,173 & $-0,003$ & 1,852 & 9.790 & 3,617 \\
\hline 3 & 6.747 & 0,125 & 0,121 & $-0,004$ & 2,846 & 6.953 & 6,118 \\
\hline 4 & 5.046 & 0,097 & 0,091 & $-0,006$ & 4,774 & 5.396 & 22,667 \\
\hline 5 & 4.767 & 0,079 & 0,086 & 0,007 & 6,113 & 4.394 & 31,583 \\
\hline 6 & 3.912 & 0,067 & 0,07 & 0,003 & 2,821 & 3.727 & 9,189 \\
\hline 7 & 3.271 & 0,058 & 0,059 & 0,001 & 1 & 3.226 & 0,619 \\
\hline 8 & 2.840 & 0,051 & 0,051 & 0 & $-0,01$ & 2.837 & 0,003 \\
\hline 9 & 2.887 & 0,046 & 0,052 & 0,006 & 6,745 & 2.559 & 42,097 \\
\hline Total & 55.626 & 1 & 1 & - & $* * *$ & $* * *$ & 118,036 \\
\hline
\end{tabular}




\section{TABLE 8}

Interior Region

\begin{tabular}{|c|c|c|c|c|c|c|c|}
\hline Digit & $\begin{array}{c}\text { Quantity } \\
\text { Observed }\end{array}$ & $\begin{array}{c}\text { Newcomb- } \\
\text { Benford } \\
\text { Law }\end{array}$ & $\begin{array}{c}\text { Proportion } \\
\text { Observed }\end{array}$ & Deviation & $\begin{array}{c}\mathbf{Z} \\
\text { Value }\end{array}$ & $\begin{array}{c}\text { Expected } \\
\text { Count }\end{array}$ & $\chi^{2}$ \\
\hline 1 & 14.417 & 0,301 & 0,297 & $-0,004$ & 1,915 & 14.592 & 2,096 \\
\hline 2 & 8.513 & 0,176 & 0,176 & 0 & $-0,006$ & 8.532 & 0,043 \\
\hline 3 & 6.109 & 0,125 & 0,126 & 0,001 & 0,659 & 6.060 & 0,4 \\
\hline 4 & 4.321 & 0,097 & 0,089 & $-0,008$ & 5,944 & 4.702 & 30,929 \\
\hline 5 & 3.980 & 0,079 & 0,082 & 0,003 & 2,44 & 3.830 & 5,894 \\
\hline 6 & 3.206 & 0,067 & 0,066 & $-0,001$ & 0,872 & 3.248 & 0,544 \\
\hline 7 & 2.825 & 0,058 & 0,058 & 0 & $-0,01$ & 2.812 & 0,063 \\
\hline 8 & 2.695 & 0,051 & 0,056 & 0,005 & 4,994 & 2.472 & 20,046 \\
\hline 9 & 2.412 & 0,046 & 0,05 & 0,004 & 4,193 & 2.230 & 14,856 \\
\hline Total & 48.478 & 1 & 1 & 0 & $* * *$ & $* * *$ & 74,871 \\
\hline
\end{tabular}

TABLE 7

Summary of the municipalities observed in the costal and interior regions

\begin{tabular}{|c|c|c|c|c|c|c|c|}
\hline Digit & $\begin{array}{c}\text { Quantity } \\
\text { Observed }\end{array}$ & $\begin{array}{c}\text { Newcomb- } \\
\text { Benford } \\
\text { Law }\end{array}$ & $\begin{array}{c}\text { Proportion } \\
\text { Observed }\end{array}$ & $\begin{array}{c}\text { Deviatio } \\
\mathbf{n}\end{array}$ & $\begin{array}{c}\mathbf{Z} \\
\text { Value }\end{array}$ & $\begin{array}{c}\text { Expected } \\
\text { Count }\end{array}$ & $\chi^{2}$ \\
\hline 1 & 30.971 & 0,301 & 0,298 & $-0,003$ & 2,107 & 31.335 & 4,235 \\
\hline 2 & 18.115 & 0,176 & 0,174 & $-0,002$ & 1,69 & 18.322 & 2,345 \\
\hline 3 & 12.856 & 0,125 & 0,123 & $-0,002$ & 1,947 & 13.013 & 1,894 \\
\hline 4 & 9.367 & 0,097 & 0,09 & $-0,007$ & 7,626 & 10.098 & 52,93 \\
\hline 5 & 8.747 & 0,079 & 0,084 & 0,005 & 5,975 & 8.224 & 33,232 \\
\hline 6 & 7.118 & 0,067 & 0,068 & 0,001 & 1,284 & 6.975 & 2,933 \\
\hline 7 & 6.096 & 0,058 & 0,059 & 0,001 & 1,374 & 6.038 & 0,557 \\
\hline 8 & 5.535 & 0,051 & 0,053 & 0,002 & 2,926 & 5.309 & 9,594 \\
\hline 9 & 5.299 & 0,046 & 0,051 & 0,005 & 7,694 & 4.789 & 54,36 \\
\hline Total & 104.104 & 1 & 1 & 0 & & 104.104 & 162,08 \\
\hline
\end{tabular}

An overview of the results obtained

Generally, it is demonstrated here that the Newcomb-Benford Law is also applicable to the public expenses substantiated in the pledge notes. One notes that in the agglutination of all the municipalities, as verified in table 03 above, it is evidenced that there are problems in digits: (4), (5), (8) and (9), since the values observed in the normality test are above from $\mathrm{Z}=1.96$ (the significance level adopted was $5 \%$ ).

The graph below better visualizes the situation commented on: 


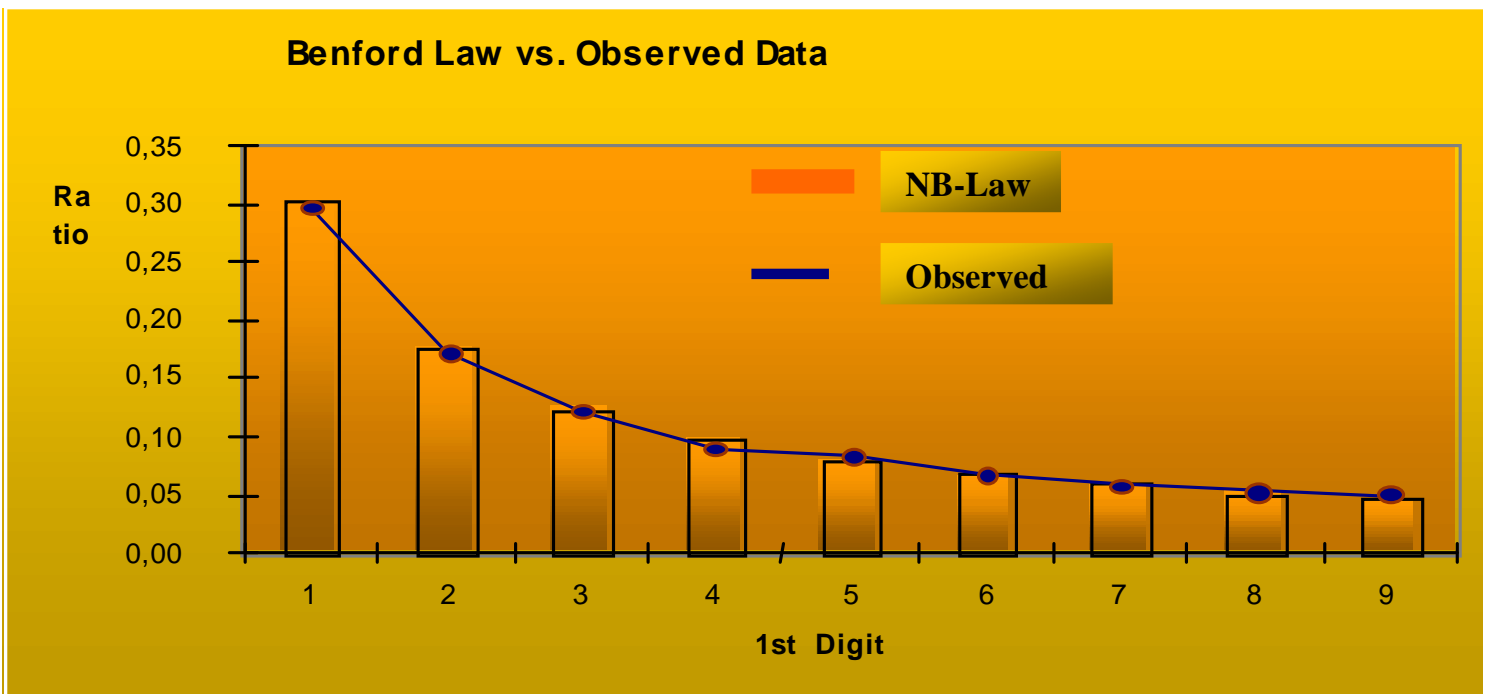

The quantitative analysis according to the Accounting Metrics model developed here reveals only that such digits do not conform to said model. Thus, the pledges with digits (4), (5), (8) and (9) show strong signs of having been manufactured or defrauded.

Below are some considerations:

- Digit (9) reveals that there is a trend of overinvoicing in the expenses made by the managers of the municipalities analyzed;

- Digit (8) discloses that there is a strong trend by the public administrator to fraction expenses above $\mathrm{R} \$ 8,000.00$, the limit established by Federal Law No. 8.666/93, which disciplines acquisitions by bid.

- Digits (4) and (5) show that the sum or combinations of the same results in a number equal or greater than (8), which clarifies the hypothesis mentioned above, i.e., that such digits are reflections of the fractioning of expenses that would undergo a bidding procedure, which is a very common practice adopted by public managers.

- Another aspect worthy of being noted is that digit (8) is not very far removed from the acceptable area delimited by the $\mathrm{Z}$ test, (digit (8) $\mathrm{Z}=2.93$ ), which did not occur with digits (4) and (5), since they fractioned expenses greater than or equal to $\mathrm{R} \$$ $8,000.00$ (digit (8)), that is, while digit (8) would be used once, digit (4), for example would be used at least twice to subdivide expenses above $\mathrm{R} \$ 8,000.00$.

It is further noted that, according to the Qui-square $\left(\chi^{2}\right)$ test, the Interior Region of the Paraíba state has a behavior that is generally better than that of the Coastal Region, even though such series are well above the acceptance are defined by the test $\left(\chi^{2}=15.507\right)$. A practical appreciation one could make, with the restrictions made with respect to subjectivity, is that in proportion to the analyses made by the state's Court of Audit, they reveal that the municipalities of the coastal region have presented more inconsistencies in the audit reports than those of the interior region of the State of Paraíba.

From the viewpoint of individual analysis of the municipalities, it was verified that only in three municipalities do the pledges behave according to the Newcomb-Benford Law, for a significance level of $10 \%$, namely: 
(L6) - what could be explained by the fact that, during the entire fiscal year of 2002, this municipality was under judicial intervention and several inspections were carried out by the Court of Audit of the State, preventing thus any illegal conduct;

(L8) - this municipality has an exemplary administration, which can be verified by the press of Paraíba. This municipality adopted the participatory budget and accounts board, consisting of several segment segments of the local society, even if presenting a small degree of variation in relation to $\chi^{2}$. (see table 1 )

(S3) - this municipality was recently emancipated (1997) and in this period, one does not find any rejection of the annual accounts.

\section{FINAL CONSIDERATIONS}

Given the above, one found that the Newcomb-Benford Law is a powerful method to assist the Auditor in detecting accounting errors, typos or accounting frauds, in the context of a Traditional Accounting Audit or Digital Audit. The Newcomb-Benford Law is studies in a simple and deductive manner in this work, as far as public expenses are concerned, whether by manipulation of monetary values, overinvoicing, improper fractioning of expenses and others.

One further highlights that it is possible to infer that the NB-Law is a powerful tool in samples planning, since errors in its definition are considerably minimized in view of the fact that knowing the natural behavior of the decimal system, statements that do not conform to the NB-Law are subject to undergo a greater concentration of audit tests as a way of validating the accounting statements.

Accounting Metrics is a scientific methodology proposed by this work for Accounting Audit, in cases where qualitative analysis does not provide the effective means for the Auditor to take a precise decision, Nigrini (2000), Hill (1998), Pinkham (1985) and Raimi (1985).

The principal strategy used here is the junction of the quantitative methods, which are the Newcom-Benford Law and the Hypothesis Tests (Z-Test and $\chi^{2}$-Test) to assist in planning the work of traditional Accounting Audit and Digital Audit. This method is used in the USA by Nigrini (2000) with certain frequency.

It was also verified that this is a scientific technology capable of determining the standard behavior of expenses practiced by public managers, since it traces the profile by which the composition of the first digit must behave.

A fact that drew a lot of attention by the authors of this work is that the analysis made by the Newcomb-Benford law could explain facts derived from qualitative analysis, since the municipalities that presented problems, according to the model adopted are those which actually have or had management problems, according to data from the Court of Audit of the State of Paraíba, while at the same time evidencing the case of the municipality, whose management quality could be considered as a model.

One should expect this work to have evidenced the importance and the possibility of adoption of accounting metrics models, capable of helping accounting professional, in the interdisciplinary context, who work with Accounting and Digital Audit.

\section{REFERENCES}

Ackoff, Russel L; Sasieni, Maurice W. Pesquisa Operacional. Rio de Janeiro. LTC. 1971 Assy Zerbini, Maria Beatriz do Amaral. Três Ensaios sobre Crédito. Tese (Doutorado em Economia) - FEA-USP. 2000. 
BENFORD, F. The Law of Anomalous Numbers. Proceeding of the American Philosophical Society, 78, 551-472, 1938.

BOYNTON, William C.; JOHNSON, Raymond N.; KELL, Walter G. Audiotria. São Paulo: Atlas, 2002.

BROWN, G.W. History of RAND'S random digits, Nat.Bur. Stds. App. Math Series, vol.12,31-32, 1951.

FREUND, Jonh E. \& SIMOM Gary A. Estatística aplicada, Economia, Administração e Contabilidade. 9 ed. Porto Alegre: Bookman, 2000

SANTOS,Josenildo dos;DINIZ,Josedilton Alves; RIBEIRO FILHO, Jose Francisco. A Lei de Newcomb-Benford: an application to determine the DNA-equivalent of expenses in the public sector. In: $3^{\circ}$ SEMINÁRIO DE USP DE CONTABILIDADE E CONTROLADORIA, 2003, São Paulo. $3^{\circ}$ Seminário de USP de Contabilidade e Controladoria 2003.

HILL, T.P: A Statistical Derivation of the Significant-Digit Law. Statistical Science (4), 354363, 1996.

HILL, T.P: Base-Invariance implies Benford's Law. Proceedings of the American Mathematical Society, 13, 887-895, 1995.

HORNGREN, Charles T. Introdução à Contabilidade Gerencial. 5.ed. Prentice-Hall do Brasil,1985.

JÚNIOR Jorge David. A Utilização de Métodos Quantitativos na Contabilidade Gerencial: Uma Abordagem Empírica. Available at: http://www.eac.fea.usp.br/artigos Visited: May 23, 2005.

LAKATOS, Eva Maria; MARCONI, Marina de Andrade. Fundamentos de metodologia científica, 3 ed. São Paulo: Atlas, 1991.

Levine, David M; Berenson, Mark L; Stephan, David. Estatística: Teoria e Aplicações Usando Microsoft ${ }^{\circledR}$ Excel em Português. Ed. LTC. 2000. Tradução: Teresa Cristina Padilha de Souza.

Matz, Adolph; Curry, Othel J; Frank, George W. Contabilidade de Custos. $1^{\mathrm{a} e d}$, $3^{\mathrm{a}}$ tiragem (2 volumes). São Paulo: Atlas Atlas. 1976.

Newcomb, S.: Note on the Frequency of Use of the Different Digits in Natural Numbers, AJM, 4, 39-40, 1881.

NIGRINI, M.J.. Digital Analysis Using Benford's Law: Tests ? Statistics for Auditors. Global Audit Publication, Canada, 2000.

NIGRINI, M.J.. Linda, J.M. The Use of Benford's Law as an aid in Analytical Procedures. Audit: A Journal of Practice and Theory 16, 52-67, 1997.

PINKHAM, R.S. On the Distribution of First Significant Digits. Annals of Mathematical Statistics, 32, 1223-1230,1961.

RAIMI, R. The Peculiar Distribution of First Significant Digits. Scientific American, 221 (6), 109-120 (1969).

SMAILES, Joanne \& MCGRANE, Ângela. Estatística aplicada à Administração com Excel. São Paulo: Atlas, 2002.

TSAO, N.R. On the Distributions of Digits and Roundoff Erros. Communications of the Association for Computing Machinery, 17, 269-271 (1974).HORNGREN, Charles T., FOSTER, George , DATAR, Srikant M. Contabilidade de Custos; tradução José Luiz Paravato. 9.ed. Rio de Janeiro: LTC, 1997. 